\title{
ANÁLISE DA PRAXIS PEDAGÓGICA DE EDUCAÇÃO AMBIENTAL NAS DISCIPLINAS CIÊNCIAS E GEOGRAFIA, MODALIDADE EJA
}

\author{
Natana da Silva Lins ${ }^{1}$ \\ Nayra Nascimento Bomfim Fernandes ${ }^{2}$
}

Resumo: A Educação Ambiental é condição fundamental para a formação do futuro cidadão, cabendo a nós, professores, capacitar os alunos incluindo em nossos planejamentos, conteúdos que abordem problemas e soluções socioambientais. A Educação de Jovens e Adultos é uma modalidade de ensino que se propõe a atender a um público com faixa etária elevada em comparação aos indivíduos matriculados no ensino regular. Partindo-se desta premissa, por meio de metodologias participativas, objetivou-se obter, por meio da produção de documentário e cordel, a práxis pedagógica da Educação Ambiental, modalidade EJA, nas disciplinas Ciência e Geografia lecionadas na escola municipal Ney Braga, na cidade de Governador Newton Bello (MA).

Palavras-chave: Educação Ambiental; EJA; Práxis Docente; Ciência; Geografia.

Abstract: Environmental Education is a fundamental condition for the formation of the future citizen, and it is up to us, teachers, to train students, including in our plans, content that addresses socio-environmental problems and solutions. Youth and Adult Education is a teaching modality that aims to serve a public with a high age group compared to individuals enrolled in regular education. Starting from this premise, through participatory methodologies, the objective was to obtain, through the production of documentary and cordel, the pedagogical praxis of Environmental Education, EJA modality, in the subjects Science and Geography taught in the municipal school Ney Braga, in the city of Governador Newton Bello (MA, Brazil).

Keywords: Environmental Education; EJA; Teaching Praxis; Science; Geography.

\footnotetext{
${ }^{1}$ Instituto Federal de Educação, Ciência e Tecnologia do Maranhão - Campus Santa Inês. E-mail: natanalins@hotmail.com. Link para o Lattes: http://lattes.cnpq.br/2724023841181551

2 Instituto Federal de Educação, Ciência e Tecnologia do Maranhão - Campus Viana. E-mail: nayra.fernandes@ifma.edu.br. Link para o Lattes: http://lattes.cnpq.br/7101977753834893
} 


\section{Introdução}

A Educação Ambiental é condição fundamental para a formação do futuro cidadão, cabendo a nós, professores, capacitar os alunos incluindo em nossos planejamentos, conteúdos que abordem problemas e soluções socioambientais. Tratar destas questões significa orientar o aprendente a usar de forma consciente os recursos naturais, garantindo desta forma a qualidade de vida para a sociedade atual e a das futuras gerações. (BOFF, 2013; DIAS, 2009).

O meio ambiente "ecologicamente equilibrado" foi garantido a todos os cidadãos na Constituição Federal de 1988. Nela, o poder público fica incumbido de estabelecer a Educação Ambiental em todos os níveis de ensino visando à conscientização pública para a preservação do meio ambiente. O marco que instaura a inserção da Educação Ambiental na EJA de forma mais abrangente no campo das propostas, no entanto, foi a aprovação da Política Nacional de Educação Ambiental - Lei no 9.795/99. Em seu artigo 9o, inciso $V$, fica estabelecido o desenvolvimento da Educação Ambiental na Educação de Jovens e Adultos.

A Educação de Jovens e Adultos é uma modalidade de ensino específica da Educação Básica, que se propõe a atender a um público com faixa etária elevada em comparação aos indivíduos matriculados no ensino regular. Para tal, foi negado o direito à educação durante a infância e/ou adolescência, seja pela oferta insuficiente de vagas, pelas condições socioeconômicas desfavoráveis ou ainda pela defasagem no desempenho durante o período letivo.

A escola tem papel fundamental para fortalecer as bases da formação do indivíduo para a cidadania crítica e responsável, capaz de enfrentar desafios e romper os laços de submissão ante a sociedade.

É nesse contexto que as reflexões sobre as questões ambientais devem ser inseridas, uma vez que a transversalidade da Educação Ambiental visa mudar os valores nas relações entre os seres humanos e destes com o mundo que os cerca.

Um dos papéis da escola frente à Educação Ambiental é levar aos alunos, em especial àqueles que, tardiamente, ingressaram no meio escolar, novas visões do mundo onde o processo ensino-aprendizagem deve-se adequar a realidade que os cerca, o que facilitará a sua compreensão em relação aos direitos e deveres de cada cidadão diante do contexto socioambiental.

Partindo-se desta premissa, foram delimitados objetivos para a realização desta pesquisa, por meio de metodologias participativas, tais como obter a práxis pedagógica do ensino de Educação Ambiental nas séries finais do Ensino Fundamental, na modalidade EJA nas disciplinas Ciências e Geografia na escola municipal Ney Braga, na cidade de Governador Newton Bello (MA).

revista brasileira educação ambiental 
Buscou-se obter o perfil do ambiente de ensino de Educação Ambiental na disciplina de Ciência e Geografia na modalidade EJA, as condições teóricometodológicas que propiciem uma apreensão proveitosa do conteúdo de Educação Ambiental pelos discentes. E, ainda, experenciar a utilização do lúdico como ferramenta facilitadora para a expressão das perspectivas dos discentes em congruência com o conteúdo didático.

\section{Metodologia}

\section{Perfil do campo de investigação}

A obtenção deste diagnóstico voltou-se para metodologia empregada nos dois primeiros períodos letivos em turmas dos anos finais do ensino fundamental da modalidade EJA. O intervalo de aplicação das atividades analíticas compreendeu as datas de 12 (doze) de abril de 2019 (dois mil e dezenove) a 17 (dezessete) de junho de 2019 (dois mil e dezenove).

A presente pesquisa foi realizada com alunos matriculados na Educação de Jovens e Adultos (EJA) em escola pertencente à sede do município de Governador Newton Bello (MA), localizado a $300 \mathrm{~km}$ da capital São Luís (Figura 1).

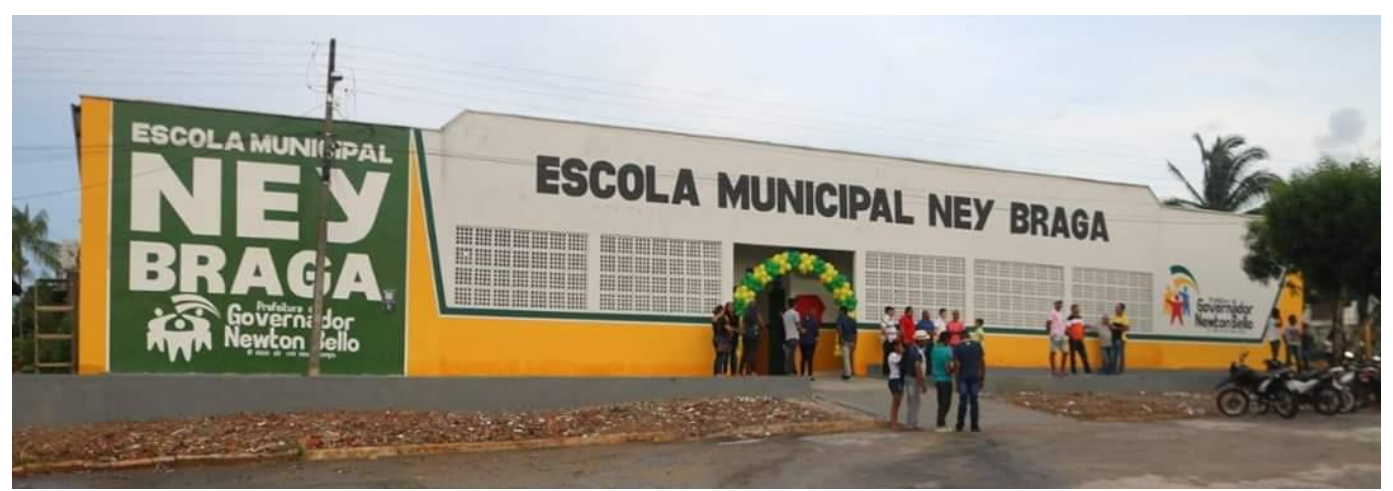

Figura 1: Faixada da Escola Mun. Ney Braga.

Fonte: Retirada do site da prefeitura de Governador Newton Bello ${ }^{3}$.

A modalidade compreende a terceira e quarta etapa do ensino fundamental. $\mathrm{O}$ estudo dedicou-se às três turmas que a referida escola dispõe. Cada turma com uma média de 25 (vinte e cinco) alunos assíduos.

A faixa etária varia de 15 (quinze) a 50 (cinquenta) anos. O público, em específico, é formado majoritariamente por adolescentes egressos de outras escolas públicas. O sexo masculino também é predominante nas três turmas.

A docente, alvo deste estudo, ministra as disciplinas Ciência e Geografia no intervalo de 4 (quatro) dias por semana, intercalando três

\footnotetext{
${ }^{3}$ Disponível em: https://www.governadornewtonbello.ma.gov.br/?s=escola+municipal+ney+braga. Acesso
} em: 15 de julho de 2019.

Revbea, São Paulo, V. 16, № 3: 126-141, 2021. 
horas/aula, de 45 minutos cada, de Ciência e Geografia em cada turma. Graduada em Licenciatura em Química, pelo campus IFMA - Zé Doca. Reside no município em que trabalha, mantendo vínculo empregatício com a instituição por meio de contrato temporário.

O fato de lecionar duas disciplinas deve-se a compensação da carga horária, que não foi contemplada integralmente pela disciplina a qual é habilitada (Ciências), portanto, teve de complementar sua carga horária, que equivale a 20 horas por semana, com a matéria de Geografia.

O prédio da escola municipal Ney Braga (Figura 1) apresenta uma estrutura física que comporta à contento todas as acomodações. Composto de 5 (cinco) salas de aula, 1 (uma) sala de informática, uma cozinha, dois almoxarifados e uma diretoria/secretaria. O corpo administrativo é composto por duas gestoras, duas secretárias e um agente administrativo. Além de uma supervisora, que semanalmente acompanha e orienta pedagogicamente.

\section{Diagnóstico participativo como instrumento de análise}

Segundo Cerqueira (2015), diagnóstico participativo é um método utilizado para fazer levantamento da realidade local. Este levantamento é feito com a participação das lideranças locais, ou por qualquer outro integrante de um grupo definido, deve conter os principais problemas da localidade em todas as áreas (social, econômica, cultural, ambiental, físico-territorial e políticoinstitucional).

Por meio de um mapeamento participativo, que pode ser interpretado como método quando não é utilizado para fins espaciais, pois apresenta-se como uma ferramenta de pesquisa para explorar as relações sociais, e sendo utilizado dessa forma, ao contrário de outros métodos de coleta, constrói relações e diálogos mais extensos entre pesquisador e pesquisado (IVR, 2010).

Tendo em vista o contexto educacional e social, no qual o público-alvo desta pesquisa está inserido, o emprego desta metodologia favorece a obtenção de um perfil realístico, à luz da singularidade de cada pesquisado e suas compreensões do tema Educação Ambiental e suas experiências.

\section{Procedimentos e recursos}

As atividades ocorreram nos dois primeiros bimestres letivos de $2019 \mathrm{e}$ consistiram em aulas de Ciência e Geografia, com cerca de 70 alunos, fato que diversificou e ampliou o olhar sobre as práticas e vivências escolares e extraescolares sobre a Educação Ambiental.

Ressalta-se que devido a coincidência da grade curricular de todas as séries contemplarem conteúdos bimestrais, que amplamente estavam voltados para a EA, as turmas foram $100 \%$ mobilizadas para a participação das atividades, não havendo nenhum procedimento de seleção dos alunos. dentre elas:

As aulas vislumbraram diversas etapas da construção do diagnóstico, 


\section{i) Aulas expositivas e dialogadas sobre os conteúdos descritos a seguir}

(Quadro 1), todos com base no referencial didático:

Quadro 1: Referências recomendadas pela Secretaria de Educação do Estado do Maranhão para docência dos anos 5\%/6ํㅡ e 7으을 do Ensino Fundamental.

\begin{tabular}{|c|l|}
\hline $\begin{array}{c}\text { SÉRIE } \\
\text { ESCOLAR } \\
\text { UTILIZADA }\end{array}$ & \multicolumn{1}{c|}{ REFERÊNCIA DIDÁTICA } \\
\hline \multirow{2}{*}{$5^{\circ}$ e $6^{\circ}$} & $\begin{array}{l}\text { Souza, Cassia Garcia de; Meneghello, Marinez; Passos, Angela. É Bom aprender - } \\
\text { edição renovada: volume 3: Educação de Jovens e Adultos - anos iniciais do ensino } \\
\text { fundamental. - 1. ed. - São Paulo: FTD, 2013. - (Coleção é bom aprender). }\end{array}$ \\
\hline \multirow{5}{*}{$7^{\circ}$ e 8 } & $\begin{array}{l}\text { Santos, Kátia de Mello Lima. Caminhar e transformar - ciências: ciência: anos finais } \\
\text { do ensino fundamental: educação de jovens e adultos / Kátia de Mello Lima Santos. - } \\
\text { 1. ed. - São Paulo: FTD, 2013. - (Coleção caminhar e transformar); }\end{array}$ \\
\cline { 2 - 2 } & $\begin{array}{l}\text { Teixeira, Maria Angélica Tozarini. Caminhar e transformar - geografia: geografia: anos } \\
\text { finais do ensino fundamental: educação de jovens e adultos / Maria Angélica Tozarini } \\
\text { Teixeira. - 1. ed. - São Paulo: FTD, 2013. - (Coleção caminhar e transformar); }\end{array}$ \\
\hline
\end{tabular}

Fonte: autoria própria.

Estas referências supracitadas são parte do acervo que a escola Ney Braga dispõe, como descrito abaixo (Quadro 2).

Quadro 2: Temas tratados com as turmas do $5 \% / 6$ e $7 \% / 8^{\circ}$ do ensino fundamental como parte das disciplinas de Ciência e Geografia.

\begin{tabular}{|c|c|c|}
\hline $\begin{array}{c}\text { ANO } \\
\text { ESCOLAR }\end{array}$ & CIÊNCIA & GEOGRAFIA \\
\hline $5^{\circ}$ e $6^{\circ}$ ano & $\begin{array}{l}\text { - Saneamento Básico; } \\
\text { o Tratamento e distribuição de } \\
\text { água; } \\
\text { - Tratamento de esgoto; } \\
\text { ○ Coleta de lixo; } \\
\text { - Reduzir, Reutilizar e Reciclar; } \\
\text { - Coleta Seletiva; } \\
\text { - Animais ameaçados de extinção; } \\
\text { - O projeto Tamar e as tartarugas } \\
\text { marinhas. }\end{array}$ & $\begin{array}{l}\text { - Os problemas ambientais; } \\
\text { - A poluição atmosférica; } \\
\text { - A poluição das águas; } \\
\text { ○ O estatuto da cidade }\end{array}$ \\
\hline $7^{\circ}$ e $8^{\circ}$ ano & $\begin{array}{ll}\text { Ol } & \text { Ecossistemas e biomas; } \\
0 & \text { A interferência humana no } \\
& \text { ambiente; } \\
0 & \text { Fatores abióticos e sua } \\
\text { importância na Terra; } \\
0 & \text { A água; } \\
0 & \text { O Ciclo da água; } \\
0 & \text { O solo; } \\
0 & \text { Os seres vivos e o solo; } \\
0 & \text { Os diferentes tipos de solo; } \\
0 & \text { Uso indevido do solo; } \\
0 & \text { O ar; } \\
0 & \text { Aquecimento global e efeito } \\
& \text { estufa. }\end{array}$ & $\begin{array}{ll} & \text { Energia e as questões ambientais; } \\
\circ & \text { Meio ambiente e sustentabilidade; } \\
\circ & \text { Recursos energéticos; } \\
\circ & \text { Fontes de energia renováveis e não renováveis; } \\
\circ & \text { O petróleo: origem e reservas mundiais; } \\
\circ & \text { O petróleo no Brasil. } \\
\circ & \text { De quem é a riqueza do pré-sal?; } \\
\circ & \text { Questão ambiental: derrames de petróleo no } \\
& \text { mar; } \\
\circ & \text { As fontes alternativas; Energia eólica; Energia } \\
& \text { solar; Energia proveniente da madeira, } \\
& \text { Termelétricas; } \\
\circ & \text { Hidrelétricas: grandes usinas, graves problemas; } \\
\circ & \text { Usinas termonucleares no Brasil. }\end{array}$ \\
\hline
\end{tabular}

Fonte: autoria própria. 
ii) produção de documentário em reflexão sobre práticas ambientalmente corretas e impactos da degradação ambiental em Governador Newton Bello, em alusão ao Dia Mundial do Meio Ambiente, 05 (cinco) de

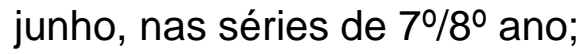

iii) criação de um cordel sobre as questões ambientais em Governaor Newton Bello, na turma de 5/6ㅇ․

\section{Aulas expositivas e dialogadas}

A docente optou por integrar uma introdução teórica dos conteúdos ao diagnóstico, mesclando com exercícios de fixação a cada aula, a fim de nortear para os conceitos mencionados a cada tópico.

O Método Expositivo e Dialogado foi uma das metodologias de ensino utilizadas durante a regência de classe. Segundo Anastasiou e Alves (2004, p. 79), este método

é uma exposição de conteúdo, com a participação ativa dos estudantes, cujo conhecimento prévio deve ser considerado e pode ser tomado como ponto de partida. O professor leva os estudantes a questionarem, interpretarem e discutirem o objetivo de estudo, a partir do reconhecimento e do confronto com a realidade.

Partindo desta premissa, a resolução de exercícios foi amplamente utilizada como forma de articular as dinâmicas entre conceituação e realidade. Confrontar os estudantes com a necessidade de seleção, organização, e a capacidade de relacionar e interpretar dados e informações, cujos resultados fundamentem decisões frente à situação-problema proposta. "A situaçãoproblema põe o sujeito em ação, coloca-o em uma interação ativa entre a realidade e seus projetos, interação que estabiliza e desestabiliza, graças às variações introduzidas pelo Educador" (Meirieu, 1998, p. 63).

\section{Documentário}

Segundo Mannheim (1952, p. 33 apud Weller et al; 2002, p. 17), toda experiência merece ser interpretada, e esse caminho é dado pelo método documentário de interpretação.

Garfinkel (1967) também foi o primeiro a reconhecer a importância do método documentário como uma forma de análise das visões de mundo e como elemento chave para a compreensão das ações e da organização social (cf. COULON, 1995; HERITAGE, 1999).

Tendo em vista a temática e a data a ser rememorada em função do calendário escolar, a docente propôs às turmas de $7 \% 7^{\circ}$ ano que sugerissem 
alguma atividade alusiva ao Dia Mundial do Meio Ambiente (dia 05/06), que devido à folga da docente, teria culminância no dia 04 (quatro) de junho, nas respectivas turmas.

Após arguirem suas posições e sugestões, definiu-se que seriam produzidos documentários com temática livre, desde que abordassem de forma contundente o meio ambiente, sua degradação e soluções para o convívio ecologicamente correto em Governador Newton Bello (MA).

A proposta objetivou-se em facilitar o registro mais realístico possível das compreensões pessoais, e como estes alunos organizar-se-iam a fim de expor suas visões segundo o que conhecem e conceituam teoricamente do tema meio ambiente, além de sua sensibilização ante ao cenário local.

As turmas $\left(7 \div / 8^{\circ} \mathrm{A}\right.$ e B) foram divididas em quatro equipes, duas em cada sala. Marcou-se um prazo de uma semana, a partir da data da proposta, para que trouxessem o esboço de suas abordagens (roteiro, tema). $O$ documentário deveria conter no mínimo $15 \mathrm{~min}$ de vídeo, abordando estritamente, e de maneira respeitosa, todo ambiente e/ou indivíduo alvo da gravação, seja ele mencionado e/ou filmado.

Para a realização do documentário, a docente deixou a critério dos alunos os tipos de equipamentos a serem utilizados, já que a escola não dispunha de recursos de mídia, além de um televisor e uma caixa de som amplificada.

Solicitou-se aos discentes que tivessem o cuidado de registrarem nitidamente os rostos e as falas dos colegas e, de quem quer que fosse filmado, assim como cartazes e os cenários que fossem escolhidos como pano de fundo.

\section{Cordel}

Luckesi (1997) afirma que, a avaliação da aprendizagem é uma técnica de investigação do professor e procura intervir na busca dos melhores resultados no processo de aprendizagem na sala de aula. Isso implica no papel do professor, que passa a elaborar atividades pautadas em métodos que facilitem a apresentação do conteúdo.

Dentro desse contexto, a docente optou por uma abordagem alternativa, aproximando os discentes do gênero literário como instrumento demonstrativo de suas realidades e observações. Para Damasceno (2011), a literatura de cordel constitui-se em um método simples de ensinar, permitindo uma maior concepção, promovendo o desenvolvimento da criatividade e competências dos alunos.

A produção do cordel sobre o meio ambiente em Governador Newton Bello - MA foi a proposta do tema, também em alusão ao Dia Mundial do Meio Ambiente. A turma incumbida desta atividade foi o $5^{\circ} / 6^{\circ}$ ano. Os parâmetros 
para a realização dessa tarefa foram os seguintes: cada aluno deveria produzir, em manuscrito, uma estrofe de no mínimo quatro versos.

O prazo estipulado para a entrega das produções foi de uma semana a partir da data de lançamento da proposta. A culminância da apresentação seria no dia 04 (quatro) de junho, tal qual nas turmas de $7^{\circ} / 8^{\circ}$ ano. A apresentação consistia na entrega à professora dos trabalhos produzidos. Por fim, a professora iria unificá-las em uma única obra.

\section{RESULTADOS E DISCUSSÃO}

\section{Perfil discente}

As turmas, de maneira geral, demonstraram inaptidão ao articularem sobre o tema meio ambiente. Quando perguntados, durante as aulas expositivas, sobre o que eles estudaram em relação ao assunto em séries anteriores, unanimemente disseram que não lembram e/ou não sabem do que trata o tema.

Isso dialoga com o que Sorrentino (1998) nos afirma, quando menciona que os grandes desafios para os educadores ambientais são, de um lado, o resgate e o desenvolvimento de valores e comportamentos (confiança, respeito mútuo, responsabilidade, compromisso, solidariedade e iniciativa) e de outro, o estímulo a uma visão global e crítica das questões ambientais e a promoção de um enfoque interdisciplinar que resgate e construa saberes.

Mais do que acarretar o aluno de conhecimento teórico, a contextualização e a empatia pela realidade social ao qual está inserido seu corpo discente, é fundamental para despertar a sensibilidade e a percepção crítica sobre o mundo que o rodeia.

Ainda sobre o desenvolvimento das aulas teóricas e resoluções de exercícios, uma maioria dos alunos empenhava-se. Quando da explanação da professora sobre os conteúdos, houve interação de uma parte significativa das turmas.

Havia o cuidado da docente em exemplificar a dinâmica teórica utilizando o cotidiano dos alunos, abordando, como instrumento de fixação do conhecimento, o dia a dia dos discentes.

Tal cenário remete ao que Freire (1970) menciona, ao dizer que o conteúdo educacional teria um papel de transformação, em que seus termos geradores, repletos de sentido para os educandos, seriam instrumentos de repensar o mundo. 


\section{Perfil docente}

A docente, com 23 (vinte e três) anos de idade, está em sua segunda experiência profissional remunerada na área da educação, tendo lecionado nesta mesma instituição dois anos antes, em turmas do Ensino Fundamental II. Nesta ocasião, era professora de Ciência e Arte.

Licenciada em Química pelo campus IFMA - Zé Doca desde novembro de 2018. De acordo com Canesin, Silva e Latini (2010, p.51) "o profissional da Química é um dos principais atores que pode atuar como um mediador da compreensão do meio ambiente e as suas relações com a Química".

Isso dialoga com Rocha (2016), quando explicita que

O educador ambiental, além de promover o desenvolvimento de conhecimentos científicos prepara os estudantes para o exercício da cidadania, a fim de que compreenda não só seu papel na sociedade, mas também se habilite a transformá-la (ROCHA et al., 2016, p. 270).

Sua abordagem, no que se seguiu dos dias letivos nos quais foram trabalhados em sala de aula os conteúdos programáticos das disciplinas Ciência e Geografia, foi pautada na participação dos alunos, ao serem instigados a expor suas visões e compreensões dos temas propostos.

A contextualização pedagógica do conteúdo científico pode ser vista com o papel da concretização dos conteúdos curriculares, tornando-os socialmente mais relevantes. Para isso, "é necessária a articulação na condição de proposta pedagógica na qual situações reais tenham um papel essencial na interação com os alunos (suas vivências, saberes, concepções), sendo o conhecimento, entre os sujeitos envolvidos, meio ou ferramenta metodológica capaz de dinamizar os processos de construção e negociação de significados" (SANTOS, 2007, p. 5).

No tocante ao aparato multimídia, ao qual é primordial para a dinamização das aulas, a professora não obteve amparo da escola, tendo acesso uma única vez, durante o período da pesquisa, à caixa amplificada para a exibição dos documentários. Não há disponibilidade de projetor multimídia ou retroprojetor no prédio.

Para a apresentação dos trabalhos foi necessário solicitar equipamento de projeção à outra instituição de ensino público municipal, que prontamente forneceu.

A insuficiência ou inexistência de recursos alternativos para auxílio do profissional docente torna enfadonha e pouco proveitosa a apreensão do conteúdo pelos alunos, tal qual afirma Oliveira, Obara e Rodrigues (2007), ao acreditarem que prender-se somente ao livro como fonte de conhecimento para Educação Ambiental, nega outros conhecimentos, como o conhecimento local, 
por exemplo, que são considerados de fundamental importância para a compreensão do mundo físico e social.

O material didático utilizado pela discente e educandos, estava defasado, dado que a vigência dos livros didáticos expirou em 2017. Neste contexto Loreto e Sepel (2003, p. 151) afirmam que "ter uma visão contemporânea de como somos e como funcionamos é um direito de todo cidadão e entendemos que seja, também, uma obrigação do estado. Somente de posse de um conhecimento atualizado podemos ser críticos em relação às informações que recebemos".

\section{Documentário: eficácia x impraticabilidade.}

Atividade sugerida às turmas de $7^{\circ} / 8^{\circ} A$ e $B$, foi realizada dentro do intervalo de uma semana a contar do dia de lançamento da proposta, com culminância no dia 04 (quatro) de junho do corrente ano. Cada turma foi dividida em dois grupos, constituídos a critério dos próprios discentes.

7응 A: a turma demonstrou ser a mais entusiasmada ao receber a proposta, no que tange ao modo como expressou empenho em realizar e, tirar dúvidas sobre os procedimentos. De antemão cogitaram ideias para a realização do documentário. Sugeriram a construção de uma maquete e, simultaneamente, iriam narrar o objetivo e sua significância para o meio ambiente newton-belense.

Isto se fundamenta quando Miranda (2008, p.21) nos diz que "trabalhar com produção de vídeo promove a melhor percepção do indivíduo sobre o mundo, uma vez que com criatividade, com criticidade e espírito investigativo propõe a interpretação do conhecimento e não apenas a sua aceitação". Possibilita-se que o aluno deixe de ser objeto e torne-se sujeito do próprio conhecimento.

No decorrer dos dias até a apresentação, um dos grupos buscou a docente durante as aulas, a fim de esclarecer dúvidas sobre a realização e a temática a ser escolhida. A professora tratou de sanar as dúvidas do grupo expondo-as a turma, com intuito de mitigar possíveis dúvidas generalizadas.

Observou-se que só um dos grupos estava realmente preocupado com a efetivação do trabalho avaliativo. Os demais não trouxeram ou demonstraram nenhum interesse sobre a obtenção do material para a apresentação.

Assim como Demo (2000) afirma que problemas na escola podem acontecer devido à falta de prazer provocada pela inadequação do ambiente escolar às expectativas sociais e culturais do aluno. Embora o interesse em aprender seja responsabilidade do aluno, o professor é parte fundamental no processo de estímulo desse interesse.

$E$, ainda, partindo dessa perspectiva é que Pinto e Tavares (2010) nos mostram que frequentemente, o que se percebe na escola é que o aluno não problematiza, não questiona, se limitando a receber e acomodar o 
conhecimento passado, de forma desvinculada da realidade em que vive. Entretanto, reconhecemos que o conhecimento se dá nas relações sujeitoobjeto-realidade com a mediação do professor.

Ao chegar o dia da culminância confirmou-se que somente um grupo concluiu a atividade. $O$ grupo (Figura 2) escolheu o tema: $A$ degradação de corpos d'água em Governador Newton Bello (MA). A equipe reuniu-se e gravou, por meio de uma câmera de um aparelho celular, um igarapé que se localiza no centro da cidade.

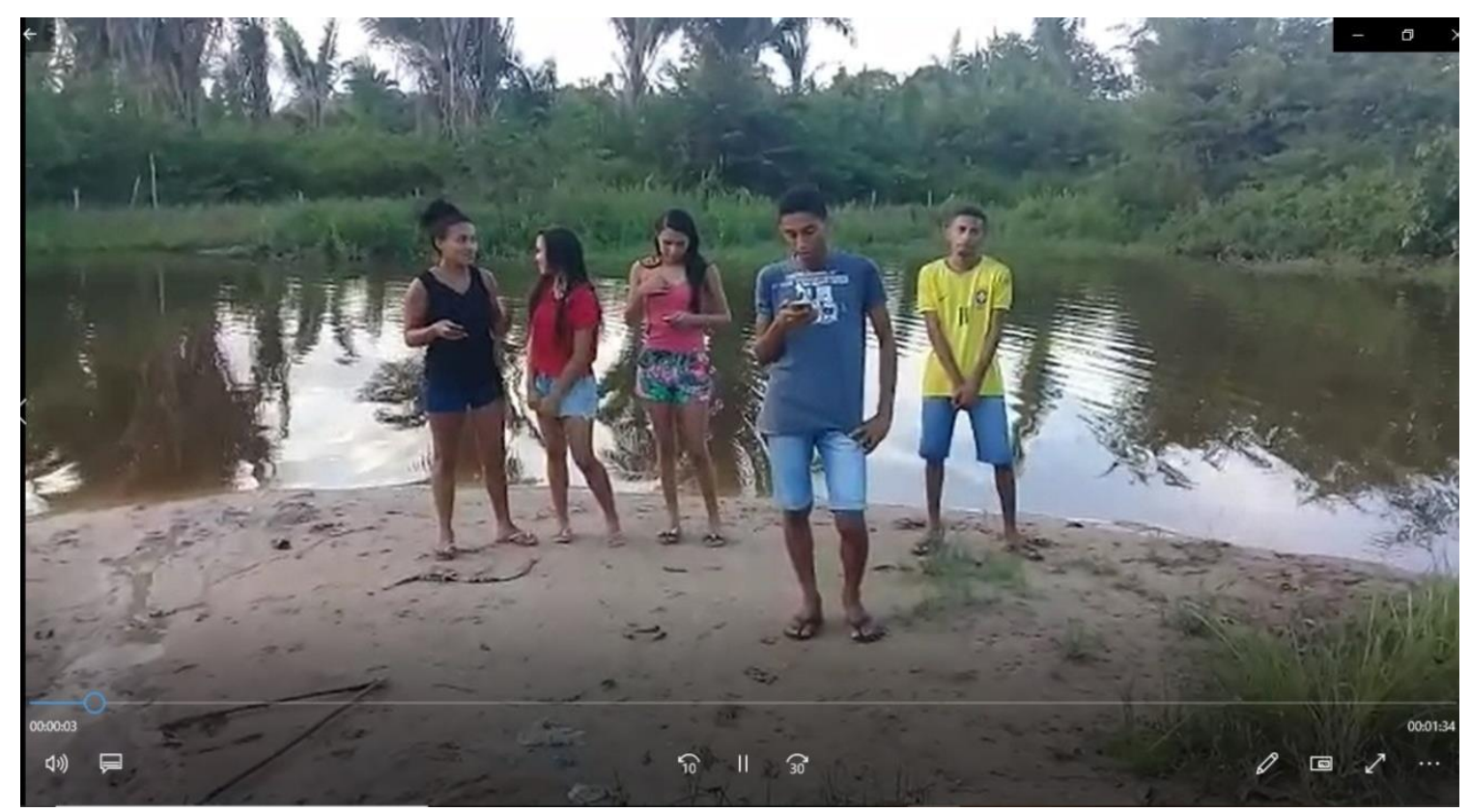

Figura 2: Trecho do documentário da equipe da turma $7^{\circ} / 8^{\circ} \mathrm{A}$.

Fonte: autoria própria.

No vídeo, eles leem trechos de assuntos que abordam o assoreamento e sua relação com o desmatamento das matas ciliares, além do depósito indevido de resíduos sólidos e dejetos das mais variadas fontes, que arruínam a qualidade do ambiente, assolando as populações que constituem esse ecossistema.

Essa percepção converge com as afirmações de Larrosa (2002, p. 21) ao descrever que "a experiência é o que nos passa, o que nos acontece, o que nos toca" a Educação Ambiental desenvolvida na pesquisa permitiu muitas experimentações partindo da singularidade dos discentes.

Ainda sobre a eficiência da abordagem, basta que verifiquemos o real intuito da Educação Ambiental, que permeia dentre suas significâncias a educação imersa na vida, na história e nas questões urgentes de nosso tempo, a Educação Ambiental acrescenta uma especificidade: compreender as relações sociedade-natureza e intervir sobre os problemas e conflitos ambientais. Neste sentido, o projeto político-pedagógico de uma Educação 
Ambiental crítica seria o de contribuir para uma mudança de valores e atitudes, contribuindo para a formação de um sujeito ecológico (CARVALHO, 2004).

70/8을 $\mathrm{B}$ Os alunos que compõem a classe foram um reflexo negativo da metodologia. Todos passaram pelo mesmo processo de explanação e arguição sobre a proposta de atividade e, também, tiveram a mesma quantidade de dias para elaboração. Concordaram, porém, não realizaram a avaliação.

Dentre os possíveis motivos destacam-se a negligência e subestima para com as disciplinas Ciências e Geografia. Trata-se de uma turma com um maior número de alunos reprovado e que apresentam indisciplina, ocasionando um déficit no desempenho em relação a turma do 7\%/8으.

A avaliação foi substituída por uma prova dissertativa em dupla, sobre o tema meio ambiente e, uma redação individual com o título: O meio ambiente em Governador Newton Bello - MA. As duas atividades compunham a nota que seria obtida através do documentário. A fim de que a turma não fosse prejudicada quanto às notas e, nem fosse de alguma maneira, beneficiada por não apresentarem o trabalho proposto.

\section{Cordel: literatura como instrumento de expressão.}

A produção do cordel pela turma de $5^{\circ} / 6^{\circ}$ ano foi realizada no dia 04 (quatro) de junho de 2019. Os alunos, em sala, escreveram e entregaram suas estrofes dentro do intervalo de 28 (vinte e oito) de maio até a culminância.

O saudosismo e a preocupação com o descarte de resíduos foi o destaque entre as produções, ficou evidente também a facilidade com a qual se expressaram, "trabalhar com o cordel eleva a ação educativa do docente, visto que, ao trabalhar conceitos de difícil compreensão, abrem-se espaços para aprimorar habilidades quanto à escrita, oralidade e interpretação de textos por parte dos alunos" (MARIA et al., 2016, p. 49).

A turma manifestou entusiasmo ao receberem a proposta de atividade. Alguns alunos expuseram que já tinham familiaridade com o gênero literário, tendo elaborado poesias em experiências pedagógicas de outras séries.

A literatura de cordel representa um recurso didático mais atrativo e mais dinâmico, uma vez que apresenta de forma lúdica diversos conteúdos do livro didático, por conta de diversos fatores, como, por exemplo: a rima, a arte, a ilustração (xilogravura), a musicalidade. E tudo isso, sem deixar de lado o contexto crítico desse recurso (SILVA et al., 2010 p. 16).

O tema do cordel foi "O meio ambiente em Governador Newton Bello MA". Aqui seguem alguns trechos: 
Escrever o belo nome de Newton Bello

Em meu coração.

O nosso meio ambiente é vivo

Como as estações

E Newton Bello é tão bela

Como lembro em meu coração.

Aluna: J. C. B. F.

Newton Bello é minha cidade

Que eu prezo com pureza.

Amo muito este lugar

Como eu amo a natureza.

Aluna: J.S.

Newton Bello está completo

Um pedido vamos deixar

Não corte as árvores, nem queime.

Ajude a preservar.

Aluno: J. P. A. B.

Newton Bello é uma cidade

Que acolhe muita gente

Tem um depósito de lixo

Que é muito próximo do seu povo.

Mas, com a consciência equivocada de quem despeja esses poluentes

Agride a si e ao meio ambiente.

Aluno: J. A.C.

$\mathrm{Na}$ estrofe da aluna J. C. B. F. percebe-se um tom nostálgico. Ao ser indagada pela docente sobre o que ela relembra das paisagens newtonbelenses, ela afirma ter convivido e crescido na zona rural do município de Governador Newton Bello e que, por isso, viu a transformação do clima e vegetação, graças a intensificação do desmatamento na região.

Já a aluna J. S. descreve um sentimento de muito apreço pelo município. Ela alega que a diversidade da fauna e flora remanescente no local, propicia uma convivência muito mais agradável do que nos grandes centros urbanos.

O aluno J. A. C. cita o descarte inadequado dos resíduos sólidos urbanos. Menciona a preocupação com os danos ambientais e sociais que essa ação pode, e vem, gerando ao município de Governado Newton Bello, tais como proliferação de doenças infecciosas, como a Dengue, Zika, Chikungunya.

Denota-se a preocupação em ratificar que a paisagem local e seu bioma estão ameaçados pela intervenção inconsequente do homem. Sendo uma presença constante, em praticamente em todas as estrofes, o descarte 
irregular do lixo municipal, é o que há de mais marcante na compreensão da turma de que é algo extremamente danoso para o bem estar socioambiental.

Para Silva (2013), o cordel se mostra como um relevante elemento formativo, permitindo mais lógica e entendimento das temáticas abordadas em suas histórias. Convém dizer que além de dar vazão a criticidade, inerente ao pensar enquanto visão de mundo, o cordel facilitou a depreensão do conteúdo de maneira eficiente.

\section{Conclusões}

Com base nos resultados obtidos, ficou evidente que a práxis pedagógica foi eficaz ao tratar da EA nas duas disciplinas. A docente teve êxito ao bordar de maneira dinâmica, tornando a apresentação dos temas de maneira mais autonômica possível aos alunos.

A modalidade recepcionou as abordagens teóricas e práticas com a vivência que Ihes foi reservada. Mais do que decorar conteúdo, foi compreendido que todo o conhecimento descrito didaticamente é palpável do ponto de vista cotidiano. E mais, o aluno percebeu-se capaz de transferir, nas duas atividades, suas percepções pessoais e, agora, fundamentadas pelo conhecimento teórico.

A professora seguiu com a metodologia apesar da indisciplina de uma maioria, fruto de uma conduta social e educacional que perpassa o domínio e criticidade da docente. Além, do desamparo de recursos didático-pedagógicos, tornando o percurso docente muito mais extenuante.

A Educação Ambiental é, ainda, um desafio ao profissional da educação, pois a prática docente não é uma realidade favorável a implementação de metodologias que visem a interação dos discentes aos meios alternativos de compreensão do mundo. Entretanto, constatou-se a aplicabilidade da metodologia à luz do cotidiano de uma escola pública e da modalidade EJA.

\section{Referências}

ANASTASIOU, L. G. C.; ALVES, L. P.e. Estratégias de ensinagem. In: ANASTASIOU, L. G. C.; ALVES, L. P. (Orgs.). Processos de ensinagem na universidade. Pressupostos para as estratégias de trabalho em aula. 3. ed. Joinville: Univille, 2004.

BOFF, L. Sustentabilidade - O que é - O que não é. Petrópolis, Vozes, 2013.

BRASIL. Lei no 9.795, de 27 de abril de 1999. Institui a política nacional de Educação Ambiental. Diário Oficial da União, Poder Executivo. Brasília, DF, 27 abr. 1999. 
CANESIN, F.P.; SILVA, O.C.V.; LATINI, R.M. O olhar de um licenciando para o ensino de química e a Educação Ambiental. Revista Eletrônica do Mestrado Profissional em Ensino de Ciências da Saúde e do Ambiente, v.3, n. 2, p.50-60, 2010.

CARVALHO, I.C.M. Educação Ambiental: a formação do sujeito ecológico. São Paulo: Cortez. 2004. p. 6.

CERQUEIRA, L. Guia do Diagnóstico Participativo | Programa de Prevenção à Violência nas Escolas. Rio de Janeiro: Flacso Brasil, 2015. 10 p.

COULON, Alain. Etnometodologia. Petrópolis: Vozes, 1995.

DAMASCENO, L. A importância da literatura de cordel no cotidiano dos alunos da EJA. Trabalho de conclusão de curso (Licenciatura Artes Visuais) Universidade de Brasília, Feijó, Acre, 2011.

DEMO, P. Educação e conhecimento. Relação necessária, insuficiente e controversa. 3 ed. Petrópolis, Rio de Janeiro: Vozes, 2000.

DIAS, R. Gestão Ambiental: responsabilidade social e sustentabilidade. São Paulo, Atlas, 2009.

FREIRE, P. Pedagogia do oprimido. Rio de Janeiro: Paz e Terra, 1970.

GARFINKEL, $H$. Common sense knowledge of social structures: the documentary method of interpretation in lay and professional fact finding. In: idem. Studies in Ethnomethodology. New Jersey: Englewood Cliffs, 1967. p. 76-96.

HERITAGE, J. C. Etnometodologia. In: GIDDENS, Anthony \& TURNER, Jonathan (orgs.). Teoria social hoje. São Paulo, Editora da UNESP, 1999. p. 321-392.

IVR - INSTITUTE FOR VOLUNTEERING RESEARCHE. Using participatory mapping to explore participation in three communities - Pathways through Participation, 2010.

LARROSA, J. Notas sobre a experiência e o saber da experiência. Revista Brasileira de Educação. Rio de Janeiro, n. 19, p. 20-28, 2002.

LORETO, E. L. S.; SEPEL, L. M. N. A escola na era do DNA e da Genética. Ciência e Ambiente, v. 26, p.149-156, 2003.

LUCKESI, C. C. Avaliação da aprendizagem escolar. São Paulo: Cortez, 1997.

MARIA, J.; CÁSSIA, R.; TORRES, D. Literatura em cordel na prática educativa do PIBID. Revista Cultural e Científica do UNIFACEX. V.14, 2016, p. 43-53.

MEIRIEU, P. Aprender sim, ... Mas como? Porto Alegre: Artmed, 1998.

MIRANDA, F. M. W. Audiovisual na sala de aula: Estudo de trabalhos de produção de vídeo como instrumento pedagógico no processo de ensino aprendizagem. Fabianna Maria Whonrath Miranda. Dissertação (mestrado) - 
Universidade Estadual de Campinas, Instituto de Artes.- Campinas, SP: [s.n.], 2008. p. 21.

OLIVEIRA, A. L. de; OBARA, A. T.; RODRIGUES, M A. Educação Ambiental: concepções e práticas de professores de ciências do ensino fundamental. Revista eletrônica de Ensenanza de lãs Ciências, vol. 6, n.3, p.471 - 495, 2007.

ROCHA, N. D.; ROCHA, J. M. da; HAMMES, L. J. Educação Ambiental transformadora: epistemologia e prática educativa. Revista Eletrônica do Mestrado em Educação Ambiental, v. 33, n.2, p. 268-285, mai./ago. 2016.

SANTOS, W. L. P. dos. Contextualização no ensino de ciências por meio de temas CTS em uma perspectiva crítica. Ciência \& Ensino, vol. 1, número especial, novembro de 2007. p. 5.

SILVA, S. P. da; ARCANJO, J. G; SOUZA, H. C. B. de; SILVA, R. M. S; SOUZA, C. O. de; LUCENA, C. S. de; ARAÚJO, W. E. de; LUCENA, K. G. M. de; TENÓRIO, A. C. Literatura de cordel: linguagem, comunicação, cultura, memória e interdisciplinaridade. Raído, Dourados, MS, v. 4, n. 7, p. 303-322, jan./jun. 2010. p. 16.

SILVA, S. R. S. O cordel pilando (re)elaborações de valores comunais e perspectivas de educar: A pedagogia de onça. 2013.

SORRENTINO, M. de Tbilisi a Tessaloniki. A Educação Ambiental no Brasil. In: JACOBI, P. et al. (orgs.). Educação, meio ambiente e cidadania: reflexões e experiências. São Paulo: SMA. 1998. p.27-32.

WELLER, W; SANTOS, G; SILVEIRA, R. L. L. da; ALVES, A. F. KALSING, V. S. S. KARL MANNHEIM E O MÉTODO DOCUMENTÁRIO DE INTERPRETAÇÃO: uma forma de análise das visões de mundo. Sociedade e Estado, Brasília, v. XVIII, n. 2, p. 375-396, jul./dez. 2002. 